\title{
Current approaches in gestational diabetes mellitus
}

\author{
Ahmet Peker $\odot$, Hakan Yarkıcı®, Harun Akar $\odot$ \\ Department of Internal Medicine, University of Health Sciences, İmir Tepecik Training and Research Hospital, İzmir, Turkey
}

DOI: $10.18621 /$ eurj.413973

\begin{abstract}
Gestational diabetes mellitus (GDM) is one of the most common medical complications in pregnancy and has become a global public health issue in terms of causing fetal and maternal morbidity and mortality in shortand long-term. The number of cases of GDM all over the world has been increasing day by day and they include risks for mother and baby health compared to healthy pregnancies. GDM screening and diagnostic phase has complete different approaches and there is no common consensus. Once GDM is diagnosed, pharmacologic treatment can be necessary in addition to strict blood sugar follow-up, regular exercise, and diet regulation. In postpartum period, medical monitoring is also necessary due to increased risk of diabetes mellitus in women with GDM. In this paper, we will also discuss approaches suggested in the GDM in the context of current guidelines and literature.
\end{abstract}

Keywords: Hyperglycemia, pregnancy, gestational diabetes mellitus, current approaches

Received: April 9, 2018; Accepted: June 14, 2018; Published Online: September 13, 2018

G estational diabetes mellitus (GDM) is the most common complication of pregnancy and is defined as glucose intolerance at various grades beginning in pregnancy in women with carbohydrate intolerance or diagnosed for the first time during pregnancy [1]. The incidence of GDM has been increasing worldwide with the effect of factors such as increased obesity rates and advanced maternal age [2]. The prevalence of GDM varies widely depending on the population and diagnostic criteria. The global prevalence of GDM varies from $1 \%$ to $28 \%$, depending on population characteristics (maternal age, socioeconomic status, race, body composition, etc.), screening methods and diagnostic criteria [3]. In a limited number of studies conducted in different regions of Turkey, it was reported that the prevalence of GDM varied between $3 \%$ and $9.2 \%$, and this ratio increased up to $11.4 \%$ depending on the diagnostic criteria used [4-6].

\section{Pathophysiology}

In the formation of gestational diabetes, the main problem is a decrease in maternal insulin sensitivity [7]. In normal pregnancy, fasting blood sugar and $\mathrm{HbA} 1 \mathrm{c}$ levels are lower than those of non-pregnant women due to peripheral use of glucose, increased glycogen storage in tissues and increased fetal glucose utilization. A decrease in maternal $\mathrm{HbA} 1 \mathrm{c}$ and fasting blood sugar are caused by the supply of glucose into fetus with active transport through facilitated diffusion and trophoblasts via glucose transporter-1 (GLUT-1), in other words, are caused by the diffusion of glucose over a wider area [8]. During pregnancy, a progressive insulin resistance occurs due to the effects of diabetogenic hormones secreted from the placenta (growth hormone, corticotropin-releasing hormone [CRH], placental lactogen, progesterone), maternal postprandial blood glucose level is elevated, and this

Address for correspondence: Ahmet Peker, MD., University of Health Sciences, Izmir Tepecik Training and Research Hospital, Department of Internal Medicine, Izmir, Turkey 
process leads to fetal glucose transport [9]. The formation of maternal insulin resistance is also influenced by agents that decrease insulin sensitivity such as tumor necrosis factor alpha (TNF- $\alpha)$, leptin, adiponectin, and resistin [10]. In a recent study, it was reported that Interleukin-6 (IL-6), an inflammatory marker, could be used as a predictor of GDM development regardless of adipose tissue, especially in the first 3 months [11]. Insulin secretion increases especially in the first trimester of pregnancy depending on the change in insulin sensitivity during this physiological adaptation during pregnancy. This increase in insulin secretion is crucial for cellular proliferation, tissue development and differentiation. If increased insulin requirement cannot be met in the long-term, GDM develops due to impaired beta-cell function [12].

\section{Genetic Factors Associated with GDM}

The increased risk of type 2 diabetes mellitus (DM) in patients with GDM in the later stages of life suggests that this disease is a polygenic, heterogeneous disease similar to type 2 DM. Genetic studies suggested that some genes associated with insulin secretion, insulin and insulin receptors, GDM and play a role in the pathogenesis of GDM, especially mutations in $\mathrm{KCNJ} 11$ and $\mathrm{ABCC} 8$ genes, which causes impairment of insulin secretion [13].

\section{Fetal and Maternal Consequences of GDM}

Many studies in the literature indicate that increased maternal glucose levels have negative consequences for both mother and fetus. As noted in the Hyperglycemia and Adverse Pregnancy Outcome study (HAPO), increased maternal blood glucose level can cause multiple complications for both fetus and mother, independent of factors such as body mass index (BMI) and weight gain [14]. If gestational betacell compensation secondary to decreased insulin sensitivity is not achieved in the long term, it causes beta-cell insufficiency and loss of function, resulting in progression of hyperglycaemia and DM. The fact that the women developed GDM have intolerance to high levels of insulin secretion for a long time, is associated with mild inflammation such as obesity, and decreased adiponectin released from adipose tissue, and the addition of factors related to individual sus- ceptibility to this condition. Type 2 DM occurs as a result of long-term destruction of beta-cells and loss of function. In addition, pregnancy causes a threefold increase in the risk of developing DM following GDM and a prolonged period with insulin resistance, independent of the well-known effects of weight gain [1517]. It was reported that the prevalence of hypertension development secondary to hyperinsulinemia associated with weight gain and sodium retention in women with GDM has been increased [18]. In the HAPO study, women with GDM with a high body mass index were reported to have a significantly higher risk of developing preeclampsia than women with GDM with a low body mass index [14]. It was shown that the risk of preeclampsia in women with GDM due to the presence of adverse factors such as impaired angiogenesis, endothelial damage, oxidative stress, and abnormal cytotrophoblastic invasion were higher compared to healthy pregnancies [19]. In particular, women with type 1 or type $2 \mathrm{DM}$ were advised to use aspirin at a low dose of $60-150 \mathrm{mg} /$ day (normal dose $81 \mathrm{mg} /$ day) from the end of first trimester until delivery to reduce the risk of preeclampsia. The US Preventive Services Task Force recommended the use of low-dose aspirin ( $81 \mathrm{mg} /$ day) as a prophylactic agent after 12 weeks of gestation in women at high risk of preeclampsia, based on the results of clinical trials [20]. Women with GDM have a increased risk of preterm labor, shoulder dystocia, polyhydramnios, urinary system and pelvic infection compared to the normal population [21]. It has been reported that if glycemic control is not achieved in GDM, the risk of stillbirth is increased 4-fold. In recent years, lower stillbirth rates have been observed with close followup of GDM and insulin treatment. In a study population consisting of women with GDM, the stillbirth rate was found to be about 1.4 per 1000 births [22, 23]. Although the mechanism of pregnancy induced retinopathy is not clearly demonstrated, it has a severe clinical course, so women who have previously type 1 or type $2 \mathrm{DM}$ and planned to become pregnant or conceived should be informed about the risk of developing and/or progressing diabetic retinopathy. Comprehensive eye examinations should be performed before pregnancy or in the first trimester. Patients should also be followed-up in terms of grade of retinopathy in each trimester and within 1 year after birth [24]. 


\section{Fetal Complications}

Complications such as macrosomia, shoulder dystrophy, brachial plexus injury, spontaneous abortion, hyperbilirubinemia, neonatal hypoglycaemia, hypocalcemia, neonatal respiratory distress, hypertrophic cardiomyopathy and congenital malformations may be seen as a result of fetal hyperinsulinemia caused by maternal hyperglycemia in GDM [25]. According to the Pedersen hypothesis, the incidence of obesity and Type $2 \mathrm{DM}$ in infants born from women with GDM was shown to be increased compared to those born from women without GDM due to effects of intrauterine hyperglycemia-related fetal $\beta$-cell hypertrophy on adipose tissue [26].

\section{Screening and Diagnosis for GDM}

Although there is no common consensus among GDM guidelines in the GDM screening, it is very important to determine the clinical risk in terms of GDM during the first visit of the patient during pregnancy, and to progress rapidly to screening if the patient has a high risk in order to prevent complications related to GDM [27].

\section{Risk Factors for Gestatıonal Diabetes Mellitus [28]}

- The presence of GDM in prior pregnancy,

- The diagnosis of glucose intolerance in the pre-pregnancy period,

- A family history (especially in the first-degree relatives) of T2DM,

- A history of macrosomia and polyhidramnios in the previous pregnancy,

- Maternal wait gain $(>20 \mathrm{~kg})$ in the previous pregnancy,

- The presence of a fasting blood glucose level $>95 \mathrm{mg} / \mathrm{dL}$ and glucosuria,

- $\quad$ Overweight (BMI $>25 \mathrm{~kg} / \mathrm{m} 2)$,

- $\quad$ Advanced age ( $>40$ years),

- $\quad$ Polycystic over syndrome

If the patient has one of the high risk factors in first prenatal visit, an oral glucose tolerance test (OGTT) should be performed based on the diagnostic criteria for diabetes mellitus in the non-pregnant population for unidentified diabetic patients [28].

Overt Diabetes Mellitus Diagnostic Criteria [28]

- $\quad$ A fasting plasma glucose ( $\geq 8$ hours fasting) level $\geq 126 \mathrm{mg} / \mathrm{dL}$

- $\quad$ OGTT second hour Plasma glucose PG $\geq 200$ $\mathrm{mg} / \mathrm{dL}$ (with $75 \mathrm{~g}$ glucose)

- $\quad$ Random Plasma glucose PG $\geq 200 \mathrm{mg} / \mathrm{dL}+$ Symptoms of diabetes

- $\quad \mathrm{HbA} 1 \mathrm{c} \geq 6.5 \%$

If high risk factors have not been identified, the recommendations of current guidelines are to make OGTT at 24-28 weeks in all pregnant women. The suggested approach for OGTT is pre-screening with a $50 \mathrm{~g}$ glucose test, switching to a $100 \mathrm{~g}$ glucose loading test if the $1-\mathrm{h}$ glucose value is identified between $140-180 \mathrm{mg} / \mathrm{dL}$. GDM is diagnosed if at least two values of the cut-off values of 95, 180, 155 and 140 of blood glucose levels at fasting, 1, 2 and 3hours, respectively, in the 100-gr glucose loading test. If $50 \mathrm{~g}$ OGTT is higher than $180 \mathrm{mg} / \mathrm{dL}$ in the 1 -hour blood glucose test, the patient is diagnosed directly with GDM without a $100 \mathrm{~g}$ blood glucose test [28]. Another approach recommended for diagnosis of GDM is one-step procedure using a $75 \mathrm{~g}$ OGTT. GDM can be diagnosed if at least one of the cut-off values of $92 \mathrm{mg} / \mathrm{dL}, 180 \mathrm{mg} / \mathrm{dL}$ and $153 \mathrm{mg} / \mathrm{dL}$, respectively, of 0,1 and 2 hours blood glucose levels are detected following a $75 \mathrm{~g}$ glucose loading glucose test. The one-step approach was proposed by the International Association of Diabetes and Pregnancy Study Groups (IADPSG) in 2010 and is still in use today. A $75 \mathrm{~g}$ OGTT is advantageous because the cut-off points are based on fetal complications of GDM [27]. In the American Diabetes Association (ADA) guidelines published in 2015, a one- or two-step approach is suggested based on selected community characteristics [30]. The approach adopted by the Society of Endocrinology and Metabolism of Turkey (SEMT) is the application of two-step diagnostic and screening criteria. SEMT recommends that at first two-step approach should be followed, as the 75-gram single-step OGTT may lead to pregnancies with a large number of GDM diagnoses and may cause financial problems [28].

\section{Treatment}

In order to control the maternal hyperglycemic state in GDM treatment, medical nutrition therapy (MNT), enhancement of physical activity and weight management programs are recommended. If blood 
glucose level cannot be regulated with these lifestyle changes, additional medical treatment should be initiated [31].

\section{Prevention of GDM}

The prevalence of GDM is increasing and most of GDM patients have a history of type 1 and type 2 diabetes mellitus. There is an increase in GDM and type 2 diabetes in parallel with an increased risk of obesity worldwide. According to ADA 2018 guidelines, preconceptual counselling should be considered as an integral part of primary care for all diabetic patients in the age of fertility starting from the puberty period, family planning should be recommended and effective contraception should be provided for women with childbearing potential. Preconceptional counseling using appropriate training tools should prevent unplanned pregnancies and inform the patient about the complications that may occur in pregnancy due to poor glycemic control [24]. Preconceptional glycemic control as close to normal as possible [ideally HBA1C, below $6.5 \%$ (48 $\mathrm{mmol} / \mathrm{mol})]$ reduces the risk of congenital anomalies [24]. Pre-pregnancy obesity is a risk factor for GDM and it has been suggested that dietary counseling and lifestyle modification with physical activity in the pre-pregnancy period can cause a decrease in the incidence of GDM [32].

\section{Medical Nutrition Therapy}

In the ADA 2018 guidelines, it was suggested that an individualized nutrition plan should be developed by a dietitian who is a specialist in the management of GDM for medical nutrition therapy in GDM. Dietitian nutrition plans should focus on maintaining adequate maternal and fetal health, achieving glycemic goals, and ensuring adequate caloric intake to promote proper gestational weight gain. For all pregnant women, a daily meal plan including a minimum of $175 \mathrm{~g}$ carbohydrate, at least $71 \mathrm{~g}$ protein and $28 \mathrm{~g}$ fiber should be designed [24]. In women with GDM, the daily energy requirement is recommended as $24 \mathrm{kcal}$ per day for ideal weight in obese pregnant women, $30 \mathrm{kcal}$ at the first trimester and $35 \mathrm{kcal}$ from the second trimester until delivery in non-obese pregnant women. The number of meals was recommended as 7 meals including main meals and collations [28].

\section{Exercise}

It has been reported that the regular exercise in GDM in conjunction with medical nutrition therapy would reduce the need for insulin, which increases insulin sensitivity [33]. In the American Congress of Obstetricians and Gynecologists (ACOG) 2018 guidelines, women with GDM were advised moderately aerobic exercise for at least 5 days for 30 minutes a week or for at least 150 minutes a week [34].

\section{Medical Treatment}

If hyperglycaemia cannot be controlled (a fasting plasma glucose level $>105 \mathrm{mg} / \mathrm{dL}$ or 1 -hour postprandial $>140 \mathrm{mg} / \mathrm{dL}$ ) despite 2 weeks of medical nutrition therapy and exercise in GDM, medical treatment should be initiated [28]. It was stated that the most appropriate agent to choose in medical treatment is insulin and oral antidiabetics may be used in place of methformin and glyburidine [24]. Metformin has been shown to increase risk of prematurity, although the risk of newborn hypoglycemia is lower, and the risk of maternal weight gain is reported to be less than insulin [35-37]. The use of metformin, which is used for ovulation induction in women with policystic over syndrome, during pregnancy was also reported to have no benefit to prevent spontaneous abortion and GDM [38]. Gliburidine, another oral antidiabetic agent, has been shown to have a higher rate of neonatal hypoglycemia and macrosomia than insulin in the studies conducted [35]. Similarly, in a recent retrospective study of 110.879 women with GDM, neonatal comorbidities were more common in patients receiving glyburidine when compared to those treated with insulin [39]. NICE, ACOG and IDF guidelines have indicated that these two agents can be used safely and effectively during pregnancy $[34,40,41]$ although the use of oral antidiabetic agents in the ADA guideline is limited due to limited safety in the long term [24]. Although there is no common consensus and there are different suggestions for the use of oral antidiabetic agents among guidelines, clinicians should determine the optimal treatment strategy by considering the riskbenefit profile of different treatments. The medicinally approved insulins in pregnancy include an intermediate acting human $\mathrm{NPH}$ and a long-acting insulin analogue detemir, a short-acting human regulatory insulin and rapid-acting analogues, insulin aspart and lispro. 
A long-acting insulin analogue glargine and a rapidacting insulin analogue glulisine have not yet been approved for use in pregnancy [42].

Individualized treatment should be planned when insulin therapy is to be started, because insulin dose may vary according to the patient's blood glucose level, weight, ethnicity and demographic characteristics. Insulin titration is often required to achieve targeted glucose levels due to physiological changes in pregnancy, and it is very important that the blood glucose is self-monitored on a daily basis [24]. There is usually a reduction in total daily insulin requirements during the first trimester and women, especially with type 1 diabetes, may experience increased hypoglycemia. In the second trimester, rapidly increasing insulin resistance requires an increase in insulin dose once or twice a week to achieve glycemic goals. Total insulin requirement can be planned as $0.7 \mathrm{U} / \mathrm{kg} /$ day in the first trimester, $0.8 \mathrm{U} / \mathrm{kg} /$ day in the second trimester, $0.9 \mathrm{U} / \mathrm{kg} /$ day in the third trimester, $1.0 \mathrm{U} / \mathrm{kg}$ in the term (36-40 weeks) and 1.5-2.0 U/ kg in the severe obese women [43]. Generally, a daily total dose recommended includes less than $50 \%$ of the total dose should be given as basal insulin and more than $50 \%$ of the total dose as prandial insulin, and dose titration is necessary because there is usually a slight decrease in insulin requirements towards the end of the third trimester [24].

\section{Treatment Targets and Postpartum Follow-Up}

Suggested targets at GDM include a fasting blood sugar level of $<95 \mathrm{mg} / \mathrm{dL}$, the 1 - hour postprandial level of $<140 \mathrm{mg} / \mathrm{dL}, 2$-hour postprandial level of $<120 \mathrm{mg} / \mathrm{dL}$ and $\mathrm{HbA} 1 \mathrm{c}$ level of $<6-6.5 \%$ [28]. If HbA1c can be achieved without risk of hypoglycaemia, $<6 \%$ is the most appropriate targeted value, but if the risk o hypoglycemia is high, the targeted HbA1c can reach up to 7\% [24]. National and international guidelines recommend long-term follow-up of women with GDM and all women with GDM history should receive $75 \mathrm{~g}$ glucose OGTT in terms of overt diabetes mellitus in postpartum 4-12 weeks. If plasma glucose (PG) concentrations in these assessments are normal, a new assessment should be made after 1-3 years, and patients should be trained in terms of symptoms of hyperglycemia and they should be advised to come to control if they experience such symptoms [24, 34].

\section{CONCLUSION}

As a result, GDM is a common complication that we frequently encounter in clinical practice of internal diseases and a disease that can cause severe problems in perinatal period and long term for both fetus and mother. Although there is no full consensus among international guidelines, the general approach is to screen pregnant women who have a high-risk on the first prenatal examination and all other pregnancies between 24-28 weeks for GDM. Early diagnosis and close follow-up should be aimed to reduce metabolic risks and prevent GDM-related complications.

\section{Conflict of interest}

The authors disclosed no conflict of interest during the preparation or publication of this manuscript.

\section{Financing}

The authors disclosed that they did not receive any grant during conduction or writing of this study.

\section{REFERENCES}

[1] Committee on Practice Bulletins--Obstetrics. Practice Bulletin No. 137: Gestational diabetes mellitus. Obstet Gynecol 2013;122(2 Pt 1):406-16.

[2] Murthy KS, Bhandiwada A, Chandan SL, Gowda SL, Sindhusree, G. Evaluation of oxidative stress and proinflammatory cytokines in gestational diabetes mellitus and their correlation with pregnancy outcome. Indian J Endocrinol Metab 2018;22:79-84.

[3] Jiwani A, Marseille E, Lohse N, Damm P, Hod M, Kahn JG. Gestational diabetes mellitus: results from a survey of country prevalence and practices. J Matern Fetal Neonatal Med 2012;25:600-10.

[4] Ozcimen EE, Uckuyu A, Ciftci FC, Yanık FF, Bakar C. Diagnosis of gestational diabetes mellitus by use of the homeostatis model assessment insulin resistance index in the first trimester. Gynecol Endocrinol 2008;24:224-49.

[5] Ozyurt R, Asicioglu O, Gultekin T, Gungorduk K, Boran B. The prevalance of gestational diabetes mellitus in pregnant women who were admitted to İstanbul teaching and research hospital obstetric and gynecology department. JOPP Derg 2013;5:7-12.

[6] Gurel C, Ozgun MT, Batukan C, Bagbug M. Prevalence of gestational diabetes among pregnant women attending Erciyes University medical faculty. Erciyes Med J 2009;31:323-30.

[7] Catalano PM, Kirwan JP, Mouzonz SH, Janet Kingz. Gestational diabetes and insulin Resistance: role in short and long term implications for mother and fetus. J Nutr 2003;133:1674- 
83.

[8] Desoye G, Kaufmann P. The human placenta in diabetes. In: Diabetology of Pregnancy. Djelmis J, Desoye G, Ivanisevic M. eds., Front Diabetes. Basel, Karger, 2005, vol. 17, pp. 94-109.

[9] Catalano PM, Huston L, Amini SB, Kalhan SC. Longitudinal changes in glucose metabolism during pregnancy in obese women with normal glucose tolerance and gestational diabetes mellitus. Am J Obstet Gynecol 1999;180:903-16.

[10] Desoye G, Hauguel-de Mouzon S, Shafrir E. The Placenta in diabetic pregnancy. In: Hod M, Jovanovic L, Di Renzo G, de Leiva A, Langer O. Textbook of Diabetes and Pregnancy. New York: Martin Dunitz, 2003;126-49.

[11] Hassiakos D, Eleftheriades M, Papastefanou I, Lambrinoudaki I, Kappou D, Lavranos D, et al. Increased maternal serum interleukin- 6 concentrations at 11 to 14 weeks of gestation in low risk pregnancies complicated with gestational diabetes mellitus: development of a prediction model. Horm Metab Res 2016;48:35-41.

[12] Buchanan TA, Xiang AH, Kjos SL, Watanabe RM. What is gestational diabetes? Diab Care 2007;30:105-11.

[13] Gloyn AL, Siddiqui J, Ellard S. Mutations in the genes encoding the pancreatic beta-cell KATP channel subunits Kir6.2 (KCNJ11) and SUR1 (ABCC8) in diabetes mellitus and hyperinsulinism. Hum Mutat 2006;27:220-31.

[14] HAPO Study Cooperative Research Group, Metzger BE, Lowe LP, Dyer AR, Trimble ER, Chaovarindr U, Coustan DR, et al. Hyperglycemia and adverse pregnancy outcomes. N Engl J Med 2008;358:1991-2002.

[15] Fridlyand LE, Philipson LH. Reactive species, cellular repair, and risk factors in the onset of type 2 diabetes mellitus: review and hypothesis. Curr Diabetes Rev 2006;2:241-59.

[16] Poolsup N, Suksomboon N, Amin M. Effect of treatment of gestational diabetes mellitus: a systematic review and metaanalysis. PloS One 2014;9:e92485.

[17] Peters RK, Kjos SL, Xiang A, Buchanan TA. Long-term diabetogenic effect of a single pregnancy in women with prior gestational diabetes mellitus. Lancet 1996;347:227-30.

[18] Salzer L, Yogev Y. Complications of gestational diabetes. In: Petry CJ, editor. Gestational diabetes: Origins, complications, and treatment. Chapter 5. Boca Raton: CRC Press. USA: Taylor and Francis Group, 2014;95-109.

[19] Sibai BM. Diagnosis and management of gestational hypertension and preeclampsia. Obstet Gynecol 2003;102:18192.

[20] Henderson JT, Whitlock EP, O'Connor E, Senger CA, Thompson JH, Rowland MG. Low-dose aspirin for prevention of morbidity and mortality from preeclampsia: a systematic evidence review for the US Preventive Services Task Force. Ann Intern Med 2014;60:695-703.

[21] Dirar AM, Doupis J. Gestational diabetes from A to Z. World J Diabetes 2017;8:489-511.

[22] Girz B, Divon M, Merkatz I. Sudden fetal death in women with well-controlled intensively monitored gestational diabetes. J Perinatol 1992;12:229-33.

[23] Crowther CA, Hiller JE, Moss JR, McPhee AJ, Jeffries WS, Robinson JS. Effect of treatment of gestational diabetes mellitus on pregnancy outcomes. New Eng J Med 2005;352:2477-86.
[24] American Diabetes Association. 13. Management of Diabetes in Pregnancy: Standards of Medical Care in Diabetes2018. Diabetes Care 2018;41:137-43.

[25] Anuk İnce D, Takc1 S, Gumuser R. The newborn period problems of the infants born to diabetic mothers. J Contemp Med 2014;4:115-20.

[26] Damm P. Future risk of diabetes in mother and child after gestational diabetes mellitus. Int J Gynaecol Obstet 2009;104:256.

[27] Solomon CG, Willett WC, Carey VJ, Rich-Edwards J, Hunter DJ, Colditz GA, et al. A prospective study of pregravid determinants of gestational diabetes mellitus. JAMA 1997;278:1078-83.

[28] Satman İ, İmamoglu S, Yılmaz C. TEMD Diabetes mellitus ve komplikasyonlarının tanı, tedavi ve izlem kılavuzu. 4. Bask1, Bayt Bilimsel Arastırmalar Basın Yayın Tanıtım Ltd. Sti. Ankara, 2009.

[29] International Association of Diabetes and Pregnancy Study Groups Consensus Panel. International association of diabetes and pregnancy study groups recommendations on the diagnosis and classification of hyperglycemia in pregnancy. Diabetes Care 2010;33:676-82.

[30] American Diabetes Association. Standards of medical care in diabetes-2015 abridged for primary care providers. Clin Diabetes 2015;33 97-111.

[31] Marathe PH, Gao HX, Close KL. American Diabetes Association standards of medical care in diabetes 2017. J Diabetes 2017;9:320-24.

[32] Koivusalo SB, Rono K, Klemetti MM, Roine RP, Lindstrom J, Erkkola M, et al. Gestational diabetes mellitus can be prevented by lifestyle intervention: The finnish gestational diabetes prevention study (RADIEL): A Randomized Controlled Trial. Diabetes Care 2016;39:24-30.

[33] Nascimento SL, Surita FG, Cecatti JG. Physical exercise during pregnancy: a systematic review. Curr Opin Obstet Gynecol 2012;24:387-94.

[34] ACOG Practice Bulletin No. 190 Summary: Gestational Diabetes Mellitus. Obstet Gynecol 2018;131:406-8.

[35] Balsells M, García-Patterson A, Solà I, Roqué M, Gich I, Corcoy R. Glibenclamide, metformin, and insulin for the treatment of gestational diabetes: a systematic review and metaaalysis. BMJ 2015;21:h102.

[36] Jiang YF, Chen XY, Ding T, Wang XF, Zhu ZN, Su SW. Comparative efficacy and safety of OADs in management of GDM: network meta-analysis of randomized controlled trials. J Clin Endocrinol Metab 2015;100:2071-80.

[37] Castillo WC, Boggess K, Sturmer T, Brookhart MA, Benjamin DK, Funk MJ. Association of adverse pregnancy outcomes with glyburide vs insulin in women with gestational diabetes. JAMA Pediatr 2015;169:452-8.

[38] Legro RS, Barnhart HX, Schlaff WD, Carr BR, Diamond MP, Carson SA, et al. Clomiphene, metformin, or both for infertility in the polycystic ovary syndrome. New Eng J Med 2007;356:551-66.

[39] Camelo Castillo W, Boggess K, Sturmer T, Brookhart MA, Benjamin DK, Jonsson Funk M. Association of adverse pregnancy outcomes with glyburide vs insulin in women with 
gestational diabetes. JAMA Pediatr 2015;69:452-8.

[40] National Institute for Health and Care Excellence (NICE). Diabetes in pregnancy: management of diabetes and its complications from preconception to the postnatal period. Clinical guideline NG3 (2015); 2015. Available from: www.nice.org.uk/guidance/ng3/resources/diabetes-in-pregnancymanagement-of-diabetes-and-itscomplications-from-preconcepti on-to-the-postnatal-period-51038446021.

[41] International Diabetes Federation (IDF) Clinical Guidelines
Task Force. Global guideline on pregnancy and diabetes. Brussels: International Diabetes Federation; 2009.

[42] Blumer I, Hadar E, Hadden DR, Jovanovič L, Mestman JH, Murad MH, et al. Diabetes and pregnancy: an endocrine society clinical practice guideline. JCEM 2013;98:4227-49.

[43] Ryu RJ, Hays KE, Hebert MF. Gestational diabetes mellitus management with oral hypoglycemic agents. Semin Perinatol 2014;38:508-15. 